\title{
A CASE OF CAVERNOUS HAEMANGIOMA OF SUB MANDIBULAR SALIVARY GLAND IN ADULT
}

\author{
Pradeep Balineni1, Vijai R², Saravana Sundaram S. N33, Shruthi Kamal V4
}

1 Postgraduate Student, Department of General Surgery, Saveetha Medical College, Kuthambakkam, Tamilnadu, India. 2Postgraduate Student, Department of General Surgery, Saveetha Medical College, Kuthambakkam, Tamilnadu, India. 3 Postgraduate Student, Department of General Surgery, Saveetha Medical College, Kuthambakkam, Tamilnadu, India. 4 Professor and HOD, Department of General Surgery, Saveetha Medical College, Kuthambakkam, Tamilnadu, India.

HOW TO CITE THIS ARTICLE: Balineni P, Vijai R, Sundaram SSN, et al. A case of cavernous haemangioma of sub mandibular salivary gland in adult. J. Evolution Med. Dent. Sci. 2019;8(16):1353-1354, DOI: 10.14260/jemds/2019/300

\section{PRESENTATION OF CASE}

A 48-year-old male presented to the surgical OPD with complaints of swelling in the right submandibular region for 2 months. Swelling is gradual in onset, progressive in nature, with no history of increase in size with mastication. On examination, a swelling of $2 * 1 \mathrm{cms}$ is felt in the right submandibular region, which was firm in consistency and smooth surfaced. Oral cavity examination was normal. No other swellings were palpable in the neck. Ultrasonography reported lobular heterogeneous, hypoechoic lesion in right submandibular region. Contrast enhanced computed tomography (CECT) of neck showed a well-defined homogeneous nodular lesion of size $2.6 * 1.3 \mathrm{cms}$ with no internal necrosis with multiple calcifications (Fig. 1,2) in the region of right sub mandibular gland. A preoperative fine needle aspiration showed features suggestive of reactive lymph node. Patient is planned for a surgical excision with a wearing diagnosis of submandibular lymphadenitis. Intraoperatively a smooth, spongy, mass with a feeding artery at the base is seen in the region of submandibular gland replacing it, feeding artery was ligated and cut and the swelling is excised in full (Fig. 3, 4). Post-operative histopathology of the specimen revealed a benign vascular neoplasm composed of multiple dilated cavernous spaces lined by flattened endothelial cells filled with RBC (Fig 5), many vessels show thrombi and few secondary calcifications, features suggestive of a cavernous haemangioma with secondary changes seen arising from the submandibular gland.

\section{CLINICAL DIAGNOSIS}

Submandibular Lymphadenitis

\section{DIFFERENTIAL DIAGNOSIS}

1. Submandibular Lymph Node

2. Plunging Ranula

3. A Second Branchial Cyst.

\section{DISCUSSION}

Haemangiomas of the salivary gland are not a rare entity. They are most commonly seen in the parotid gland (87\%) ${ }^{1,2}$ probably due lack of a well-defined capsule and

'Financial or Other Competing Interest': None.

Submission 05-03-2019, Peer Review 09-04-2019,

Acceptance 15-04-2019, Published 22-04-2019.

Corresponding Author:

Pradeep Balineni,

Plot No. 112, Revenue Colony,

Near SSN Degree College, MM Donka

Ongole-523002, Prakasam District,

Andhra Pradesh, India.

E-mail: pradeep052191@gmail.com

DOI: $10.14260 /$ jemds $/ 2019 / 300$

\section{(c) (i) $\$$}

neurovascular bundle in it. Haemangiomas of the salivary glands are commonly noticed in children, 2,3 but are a rare entity to be noticed in adults. Average presenting age of patients is 10 years. ${ }^{1,3}$ Sub mandibular gland haemangiomas are also rare, they represent only $12 \%$ of all the salivary gland haemangiomas, ${ }^{2}$ only 15 cases of sub mandibular haemangiomas have been reported in English literature till date. ${ }^{4}$ There is no reported literature of their aetiology, but several theories hypothesized that they may be a congenital or due to any trauma to that region.

Haemangiomas are benign vascular tumours. They are classified as cavernous type and capillary type. Capillary type is mostly seen in cases of children and cavernous type is most common in adults. ${ }^{3}$ Cavernous type are formed by dilated sinusoids lined by endothelium, capillary type is purplish, lobulated and lacks a definite capsule. They may arise from the gland oy by invasion of the subcutaneous blood vessels. ${ }^{3}$ Malignant transformation of these lesions is not reported till date. ${ }^{4}$ These benign tumours are most commonly seen females than males ${ }^{1,4}(2: 1)$ and also have a noted left sided preference. ${ }^{3}$ This female preponderance is shows that these lesions might be influenced by the circulating hormones. ${ }^{1}$

There are no much evidence of their clinical presentation, owing to the rarity of the disease. According to the review of literature of the 15 cases patients present with a painless rubbery, soft fluctuant swelling which is not related to food intake, these patients may also show a seldom skin changes which might help in clinching the diagnosis. Some patients may also complain of tender cord like structure in the floor of the mouth due to phleboliths. They are seldom misdiagnosed as chronic sialadenitis with sialolith. The other differential diagnosis would be submandibular lymph node, plunging ranula and a second branchial cyst. 1

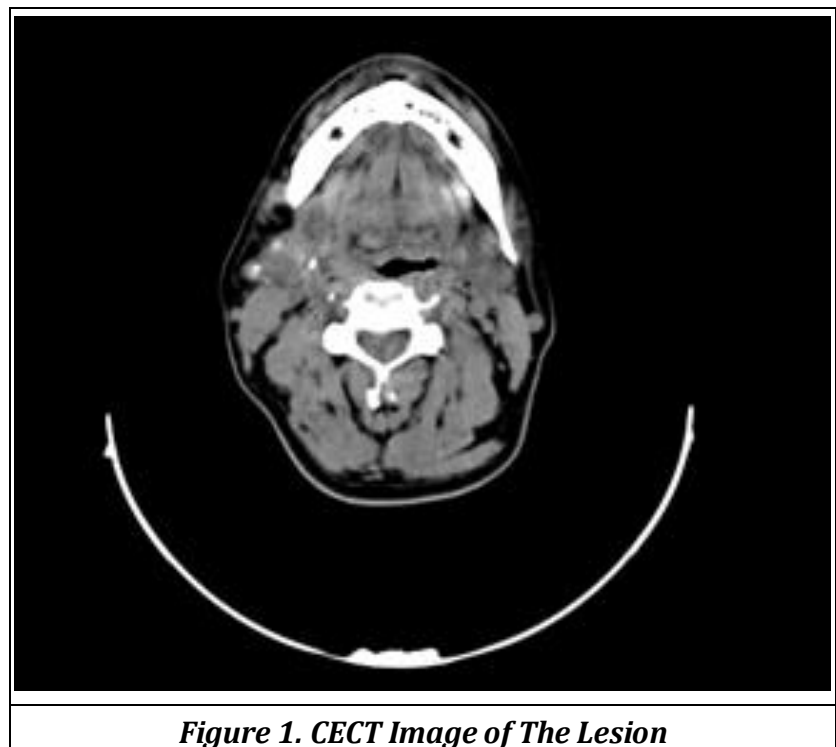



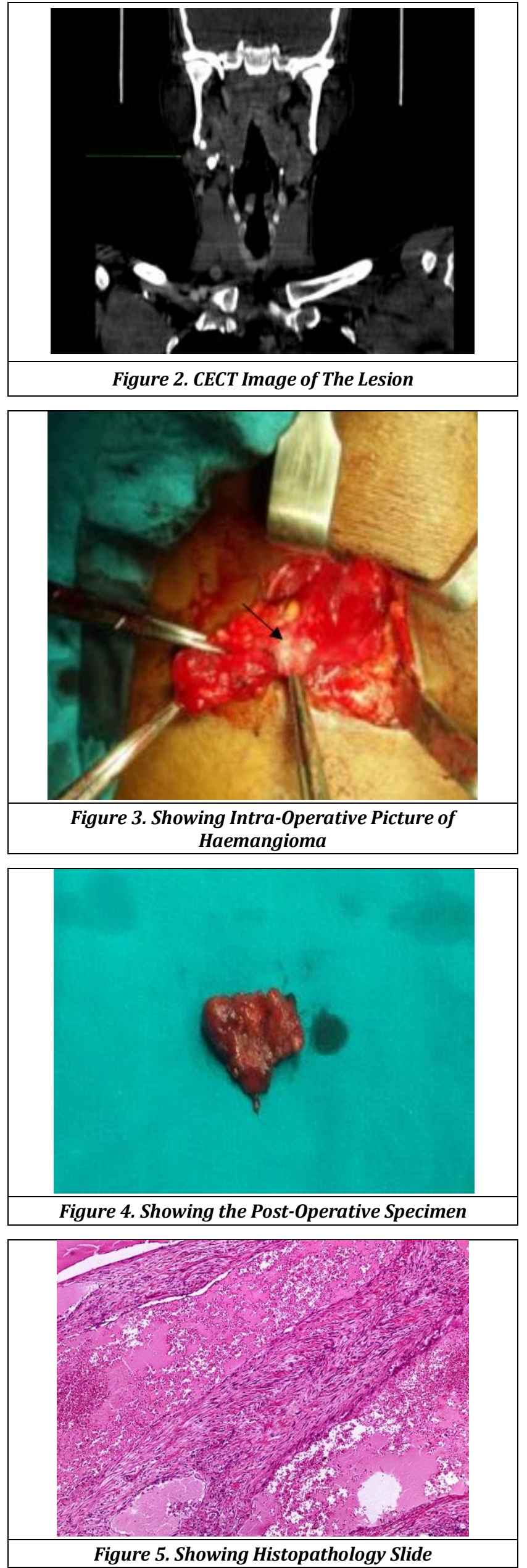

\section{DISCUSSION OF MANAGEMENT}

Radiological investigations are mostly done to rule out other benign conditions. On ultrasonography they are seen as heterogenous, hypoechoic lesions which may or may not have phleboliths. Computed Tomography (CT) scan reveals tumour as enhancing mass similar to the blood vessels. ${ }^{3,5}$ In Magnetic Resonance Imaging (MRI) on T1 weighed image, they are seen as isointense to muscle and on T2 weighed image they are hyper intense. Some authors have reported nuclear medicine imaging with $99 \mathrm{mTc}$ red blood scintigraphy as useful tool for diagnosis.3,6 A preoperative fine needle aspiration cytology (FNAC) of these lesions is not of great use. ${ }^{1}$

According to some authors, capillary haemangiomas tend to regress over a period of time, but cavernous haemangiomas are to be intervened. ${ }^{7}$ But, as preoperative diagnosis of these lesions is difficult, surgical excision would be the treatment of choice for sub mandibular haemangiomas. ${ }^{1,2,3}$ Other modalities of treatment are laser, cryotherapy, embolization and steroids. ${ }^{4}$

\section{FINAL DIAGNOSIS}

Right Sub Mandibular Salivary Gland Haemangioma ${ }^{8}$

\section{REFERENCES}

[1] Lee HJ, Kwon OJ, Lee JS, et al. A case of cavernous haemangioma in the submandibular gland: a review of clinicoradiologic features and treatment methods. Korean J Otorhinolaryngol-Head Neck Surg 2015;58(10):699-703.

[2] Singh PP, Gupta N, Jain M. Arteriovenous haemangioma involving submandibular salivary gland. Indian J Otolaryngol Head Neck Surg 2001;53(1):57-9.

[3] Chuang CC, Lin HC, Huang CW. Submandibular cavernous haemangiomas with multiple phleboliths masquerading as sialolithiasis. J Chin Med Assoc 2005;68(9):441-3.

[4] Singhal S, Virk R, Dass A, et al. Cavernous haemangioma in the submandibular gland masquerading as sialadenitis: a case report. The Internet Journal of Otorhinolaryngology 2005;4(2):14.

[5] Kumar S, Gupta AK, Bakshi J. Submandibular gland haemangioma: clinicopathologic features and a review of the literature. Ear Nose Throat J 2010;89(11):E14-7.

[6] Cho JH, Nam IC, Park JO, et al. Clinical and radiologic features of submandibular triangle haemangioma. J Craniofac Surg 2012;23(4):1067-70.

[7] McMenamin M, Quinn A, Barry H, et al. Cavernous haemangioma in the submandibular gland masquerading as sialadenitis. Case report. Oral Surg Oral Med Oral Pathol Oral Radiol Endod 1997;84(2):146-8.

[8] Nussbaum M, Tan S, Som ML. Haemangiomas of the salivary glands. Laryngoscope 1976;86(7):1015-9. 